----- Raf. J. Sci., Vol. 28, No.4, pp. 13-21, 2019------

\title{
Sepsis in Burn Patients
}

\author{
Ghassan A. Hassan \\ Ibn Al- Atheer Hospital /Microbiology Unit / Nineva Health Center \\ E-mail: ghassanssho@gmail.com
}

(Received 24/2/2019; Accepted 20/5/2019)

\begin{abstract}
One hundred blood samples and burn swabs from septicemic burn patients were collected over a period from July 2017 until may 2018 at Burn Center in Baghdad Teaching Hospital. The age of patients was between one year to sixty years and they were suffering from burn wound sepsis ,the highest number of patients was female among age group 20-29 years old. The highest frequent cause of burn was flame $78 \%$ and the least was chemical $1 \%$, it was found that flame burn patients were more vulnerable to sepsis. The mortality rate among male $56 \%$, females $48 \%$ and the highest mortality rate was $100 \%$ in the age group less than one year and more than sixty years, the least rate of mortality was $27 \%$ in the age group 10-19 years old. The number of septicemic patients 36 who is total body surface area (BSA) burned 30-39\% and the mortality in this group was 16.6\%, however the least number of patients was two of BSA $90-99 \%$ with mortality rate $100 \%$. The most frequent aetiological agents isolated from the blood of septicemic burn patients was staphylococcus aureus 34(28.1) followed by Pseudomonas aeruginosa 25(20.7), Klebsiella pneumonia 13(10.8), Streptococcal pyogenes 10(8.3), Escherichia coli 8(6.6\%) and Serratia marcescense, Acinnetobacter calcoceticus were 5(4.1) equally. The incidence of gram negative bacteria was much higher than gram positive bacteria in the septicemic burn cases, most of septicemic attack occur during the first week of admission and especially on the 7th day of staying in hospital and above, and they were much more likely to result from gram positive organism e.g S.aureus and S.pyogene. After the 1st week the septicemic attack was much more likely to result from gram negative organisms e.g. P.aeruginosa K.pneumonia, E.coli, Serratia mercescense, Acintobacter calcoceticus, $P$ vulgaris and $P$. rettger.
\end{abstract}

Keywords: Sepsis, Burn, patients.

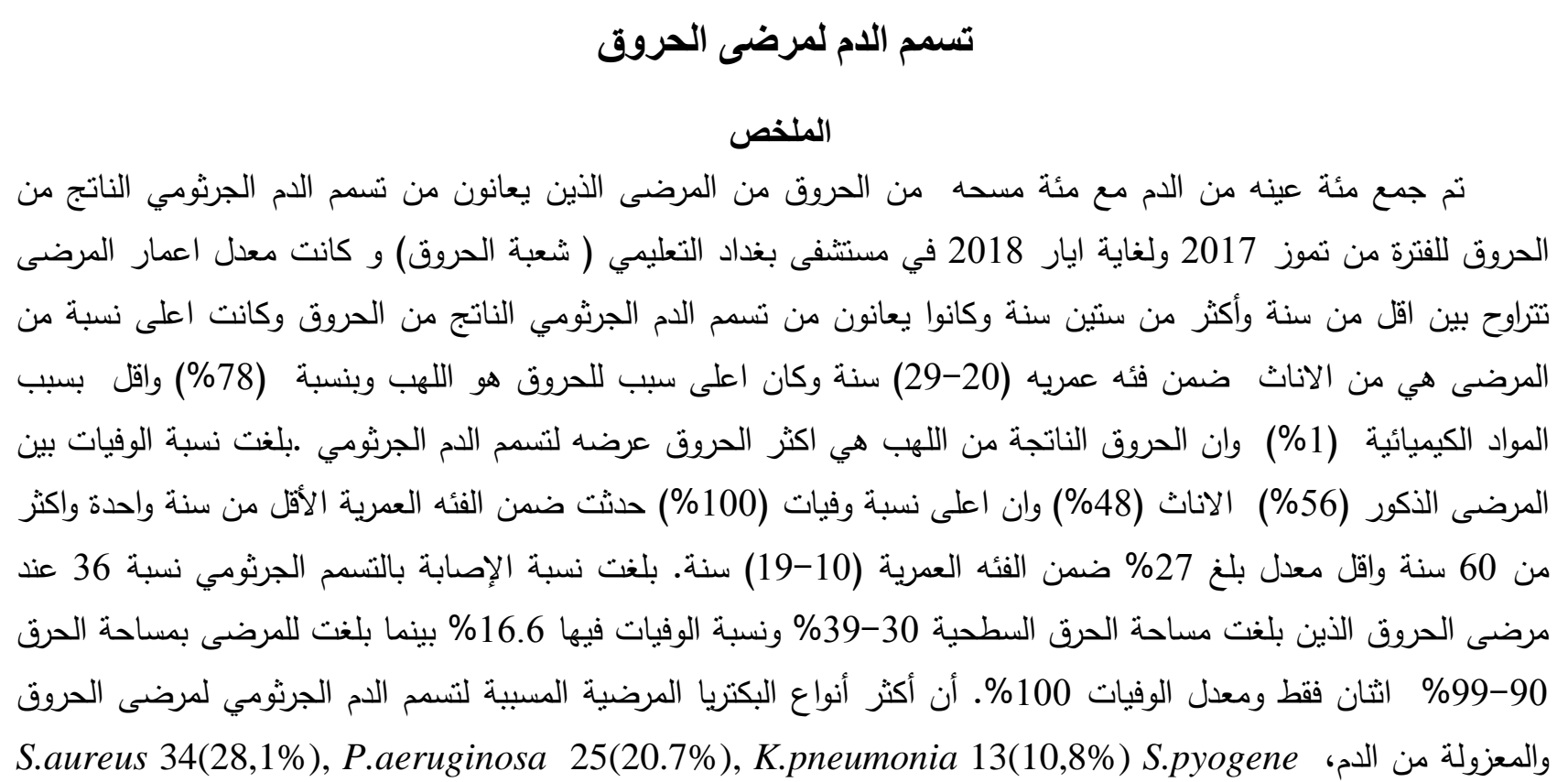


5 Acinetobacter calcoceticus 10(8.3\%), E.coli 8 (6,6\%), serratia marcescense

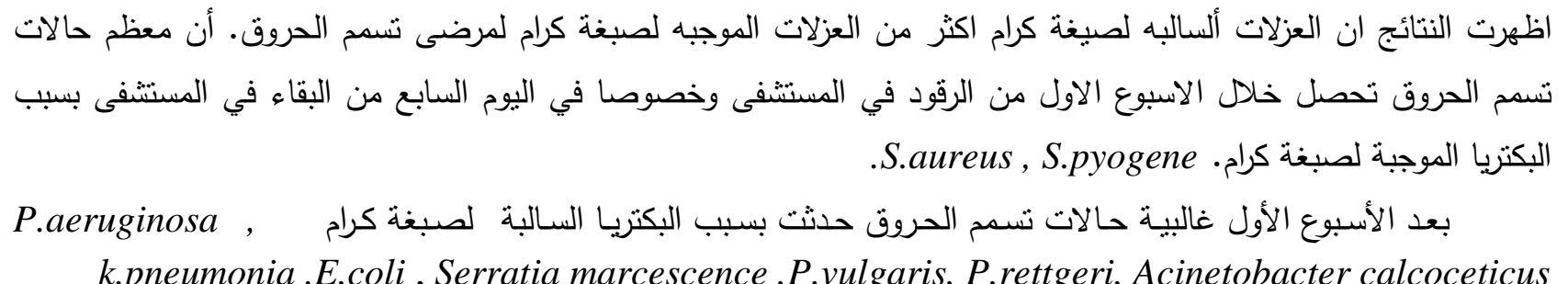
الكلمات الدالة: تسمم الدم، مرضى، الحروق.

$\longrightarrow$

\section{INTRODUCTION}

The Burn wound sepsis is probably the most serious complication in burns. Invasive sepsis occur when pathogenic organism in the burn wound multiply sufficiently to overcome the body natural defense mechanism and then actively invade the living tissues adjacent to the burn wound. If this advance remains unchecked, septicemia, active grow of organism in the blood, is a highly probable sequel (Muir et al., 2010).

The prognosis of such bacteremia or septicemia may well depend on its prompt recognition by bacteriologic means. Subsequent initiation of specific therapy based on laboratory findings may well prove to be life saving, when the classic syndrome of a septicemia (chills, fever, prostration), due to the presence of actively multiplying bacteria and their toxins in the blood stream is found, it is rarely difficult to isolate the causative organism (Liedberg et al., 2011).

Burn injury produce acute derangement of multiple host function. In generalized burn ,the effect include structural alteration of the gastrointestinal tract mucosa, this damage may predispose burn wounds to infective bacteria.

As invasion and septicemia occur, they are associated with conversion of area of partial thickness burn to area of full thickness burn to lysis and degeneration of granulation tissue with formation of a neoeschar (Pruitt, 2012). This due to damage to the tenuous blood supply caused by vascular invasion and occlusion (Cruickshank et al., 2013).

The onset may be sudden, but more often invasion is superimposed in patient who already has purulent discharge, leukocytosis and fever. Early in the process there may be increased number of non segmented neutrophils in the blood, a further elevation in white cell count, an increase in fever and occasionally chills. As the process advance the patient may become hypothermic, the white cell count may be depressed, the patient may become non responsive and the process progress to death with toxaemia (Reig et al., 2001).

A successful outcome of invasive burn wound sepsis require early detection and extremely vigorous therapy. The appearance of the wound and the general condition of the patient is taken into account in the clinical diagnosis (Sanyal et al., 2000).

The prodromal stage of gram negative septicemia may be followed by the sudden onset of septic shock with profound hypothermia, hypotension and multiple organ failure (Curtis et al., 2015). Recovery is still possible if an effective antibiotics is administered, but if treatment is further delayed or is ineffective death will almost certainly supervene (Aladin and Yousif, 2016).

Invasive sepsis and septicemia are rare during the first week post burn but if they do occur they are much more likely to result from gram positive organisms such as Streptococcus pyogenes or Staphylococcus aureus than from gram negative organisms such as Pseudomonas aeruginosa. After the first week, the converse is true (Gang et al., 2000).

Increase risk of septicemia is associated with burn over $30 \%$ body surface area (BSA), full thickness skin destruction, infancy and old age, diabetes, cardiopulmonary disease, inhalation injury, obesity and malnutrition, poor blood supply to the wound and moist warm wound environment (Gang et al., 2000; Muir et al., 2010). 
No one with major burn is safe from the complication of septicemia until burn wound is completely grafted or has healed, all intravenous catheters are removed and the patient is eating, all antibiotics has been finished, and the patient has no fever for a few days (Bauer et al., 1966).

\section{MATERIALS AND METHODS}

A total of 100 patients suffering from septicemic attack after burn were included in this study. The patients include those with infected burn wound who were suffering from septicemia as a complication of burn wound infection. The clinical diagnosis was made depending on the clinical signs and symptoms of the patients. All cases were thoroughly studied from the bacteriological point of view. Each case was carefully assessed regarding isolation and identification of the causative bacterial agents of burn septicemia.

Blood samples were collected from all patients, best time for collection before temperature rise, with adequate volume according to the age of patients. After that the blood transfer to two bottles of culture (brain heart infusion. Blood culture were incubated at 37C and examined daily throughout the first week for evidence of growth. Subculture was performed by using a sterile syringe and needle into two blood agar plate one of them for anaerobic incubation, chocolate agar plate and MacConkey agar plate. In addition, gram stains procedure to determine the presence of microorganism, at the same time subculture was done into a blood agar plate for anaerobic inoccupation into the anaerobic jar.

Swabs from infected burn wound were obtained by rubbing the inflamed or discharging area by using sterile disposable swabs were immersed in transport media before antimicrobial topical agent was used. These swabs inoculated on blood agar, MacConkey and chocolate agar at 37c ...

Bacterial identification by Gram staining, cultural characteristics by examining the growth, All biochemical tests, API.

Antimicrobial susceptibility test was carried out as described by Kirby -bauer (1966) and (Higgins, 2014) using different antimicrobial discs and interpretation of zone diameter.

\section{RESULTS}

The result showed the highest number of patients was of female 16(16\%) among age group $20-29 y$. The least frequently affected was one female and one male at age group above 60y old. However the highest No. of male patients affected was $9(9 \%)$ among age group 1-9y as shown in (Table 1) and Fig. (1).

Table 1: Distribution of 100 hospitalized septicemic burn patients according to age and
gender

\begin{tabular}{|c|c|c|c|}
\hline \multirow{2}{*}{ Age } & Male & Female & Total \\
\cline { 2 - 4 } & No. $(\%)$ & No. $(\%)$ & No. $(\%)$ \\
\hline$>1$ years & 1 & 2 & $3(100)$ \\
\hline $1-9$ & 9 & 10 & $19(100)$ \\
\hline $10-19$ & 7 & 15 & $22(100)$ \\
\hline $20-29$ & 7 & 16 & $23(100)$ \\
\hline $30-39$ & 4 & 9 & $13(100)$ \\
\hline $40-49$ & 4 & 4 & $8(100)$ \\
\hline $50-59$ & 3 & 7 & $10(100)$ \\
\hline$>60$ & 1 & 1 & $2(100)$ \\
\hline Total & $36(36)$ & $64(64)$ & $100(100)$ \\
\hline
\end{tabular}




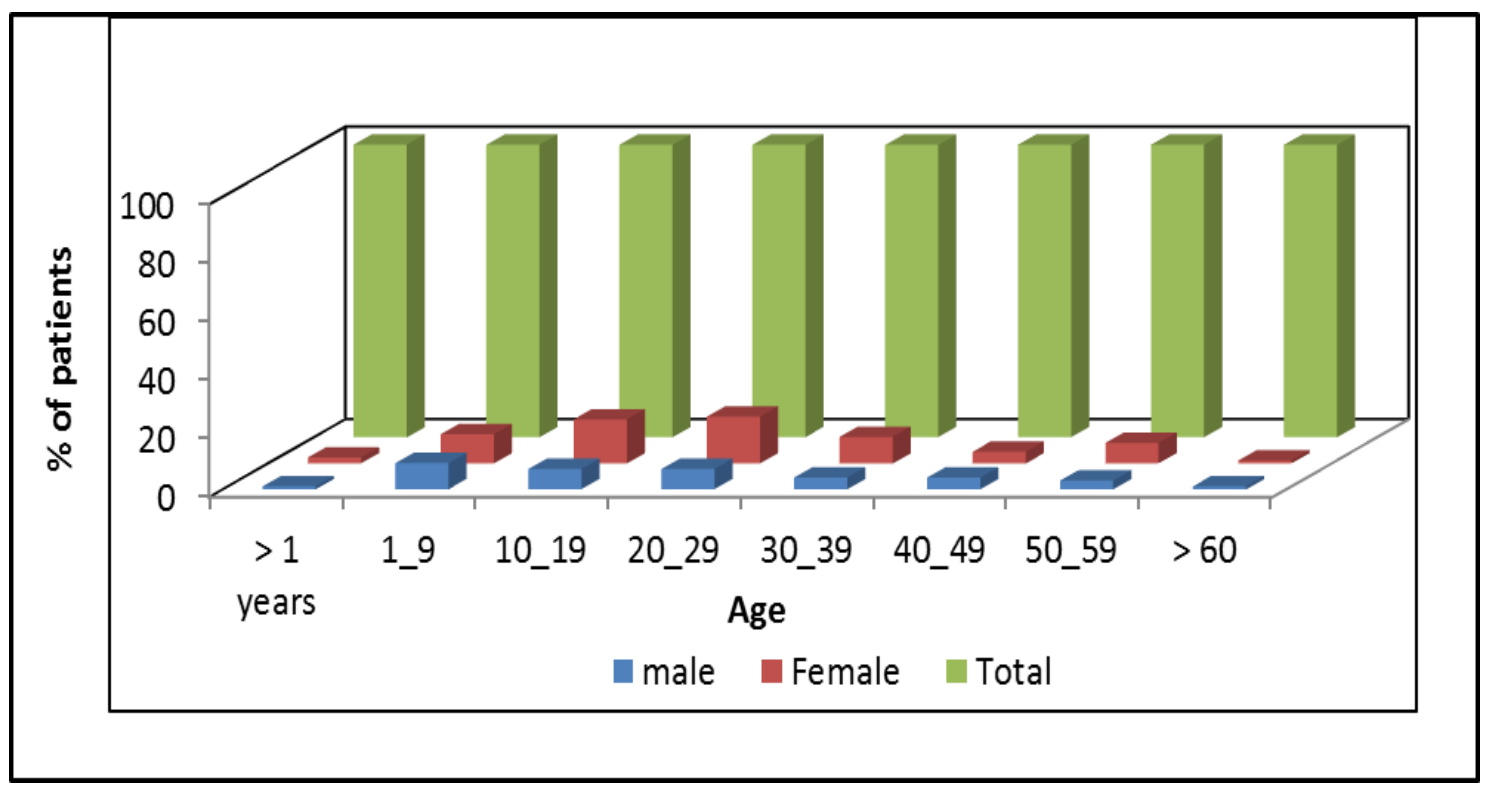

Fig. 1: Distribution of 100 hospitalized septicemic burn patients according to age and gender

The largest number of sepsis burn patients was 53 with $2^{\text {nd }}$ degree of burn depth and the mortality rate was $28.3 \%$, while the patients with the $3^{\text {rd }}$ degree of burn depth was 47 and the mortality rate was $76.96 \%$ as shown in (Table 2) and Fig. (2).

Table 2: distribution of septicemic burn patients according to burn degree

\begin{tabular}{|c|c|c|}
\hline Burn Degree & Patients No. $(\%)$ & $\begin{array}{c}\text { Death No. } \\
(\%)\end{array}$ \\
\hline $1^{\text {st }} \cdot$ degree & $0(0)$ & $0(0)$ \\
\hline $2^{\text {nd }}$. Degree & $53(53)$ & $15(28.3)$ \\
\hline $3^{\text {rd }} \cdot$ degree & $47(47)$ & $36(76.59)$ \\
\hline Total & $100(100)$ & $51(51)$ \\
\hline
\end{tabular}

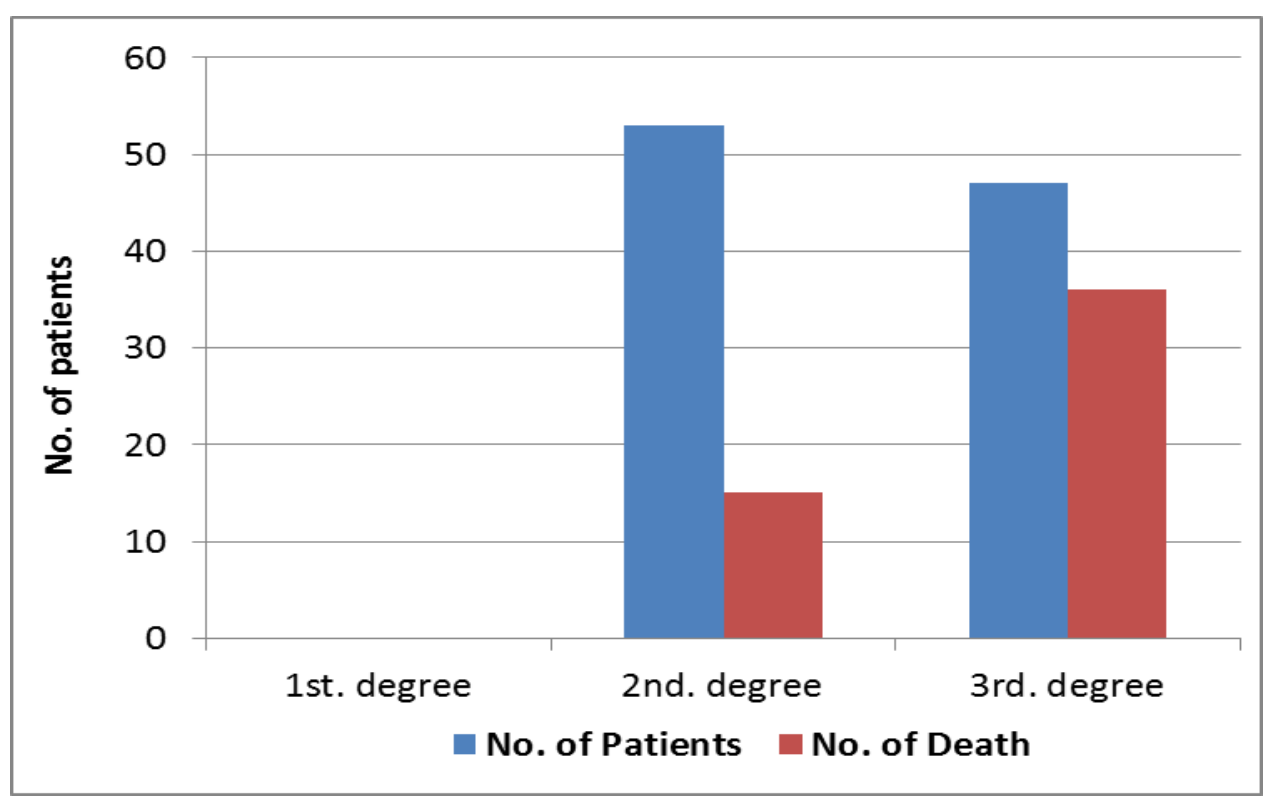


Fig. 2: distribution of septicemic burn patients according to burn degree

Sepsis occurred in burned patients in high percentage $20 \%$ at the end of the $1^{\text {st }}$ week of staying in hospital. This declined to $1 \%$ in the 12 and 13 days post burn as shown in (Table 3) and Fig. (3) the correlation between the occurrence of septicaemia with the period of staying in hospital (days post burn).

Table 3: Relationship of frequency and percentage of burn septicemia with hospital admission

\begin{tabular}{|c|c|}
\hline Hospital admission & Septicemia frequency (\%) \\
\hline 1-day & $0(0)$ \\
\hline 2-days & $4(4)$ \\
\hline 3-days & $8(8)$ \\
\hline 4-days & $10(10)$ \\
\hline 5-days & $15(15)$ \\
\hline 6-days & $18(18)$ \\
\hline 7-days & $20(20)$ \\
\hline 8-days & $10(10)$ \\
\hline 9-days & $7(7)$ \\
\hline 10-days & $3(3)$ \\
\hline 11-days & $3(3)$ \\
\hline 12-days & $1(1)$ \\
\hline 13-days & $1(1)$ \\
\hline Total & $100(100)$ \\
\hline
\end{tabular}

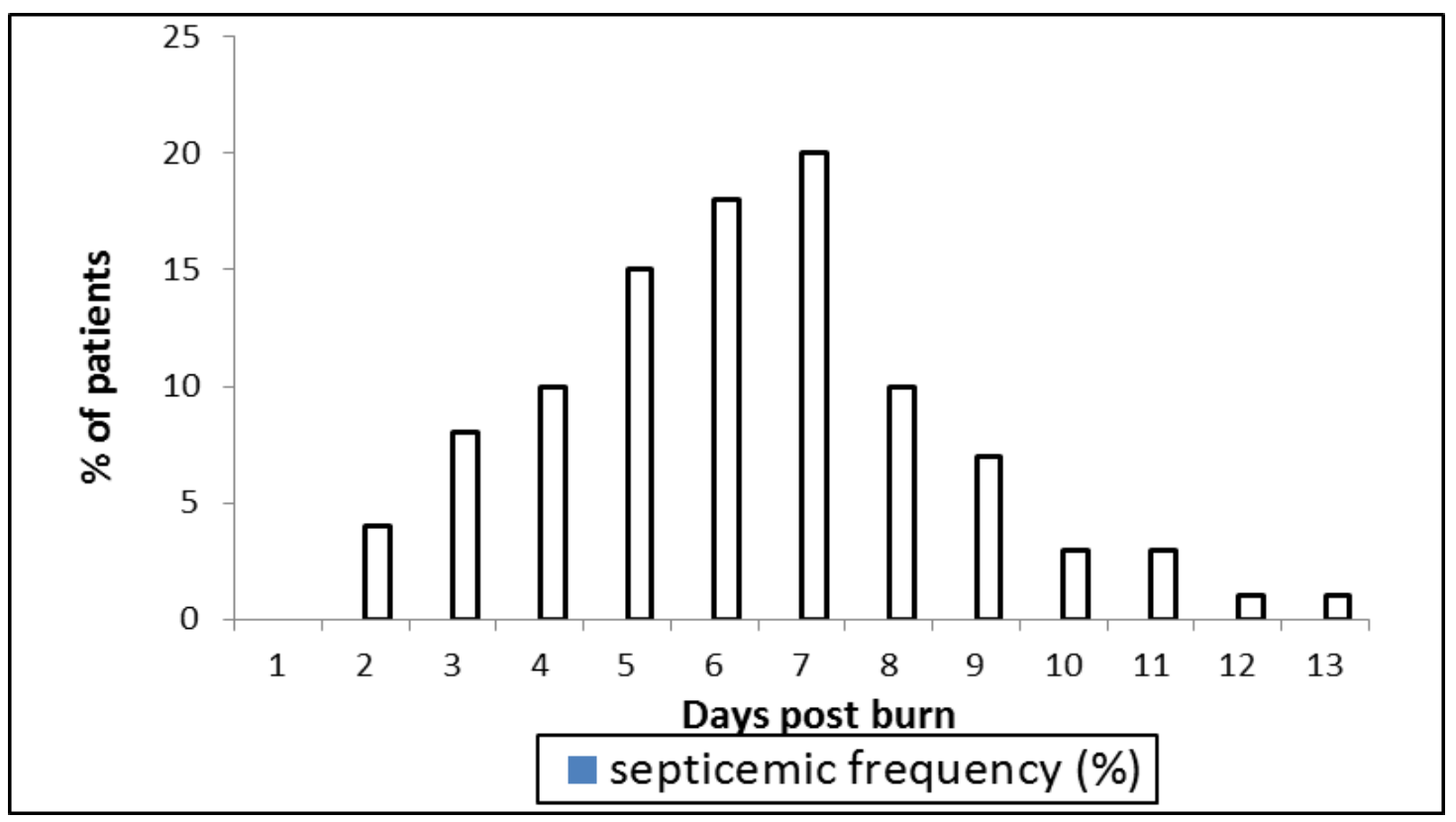

Fig 3: Relationship of frequency and percentage of burn septicemia with hospital admission

The largest number of dead septicemic burn patients were with catheter 37 and ten of them died on the $5^{\text {th }}$ day, while the number of the dead sepsis patients who were without catheter was 14 and four of them died on the $6^{\text {th }}$ day.

Majority of sepsis patients $70 \%$ had no medical history while $27 \%$ were heavily smokers, $5 \%$ of the female patients were pregnant and $3 \%$ were alcoholic.

Most common aerobic organism isolated from the blood of septicemic burn patients was S.aureua 34(28.1) followed by P.aeruginosa 25(20.7\%) K.pneumonia 13(10.8\%), S.pyogene 
10(8.3\%), E.coli 8(6.6\%), Serratia marcescense and Acinetobacter calcoceticus $5(4.1 \%)$ equally as shown in (Table 4).

Table 4: Bacteria and fungi isolated from blood cultures of septicemic burn patients

\begin{tabular}{|c|c|c|c|c|c|}
\hline \multirow{2}{*}{ Acrobic Bacteria } & \multirow{2}{*}{ 焉 } & \multicolumn{2}{|c|}{ No.\&(\%) of isolates from } & \multirow{2}{*}{$\begin{array}{r}\text { Total } \\
(\%)\end{array}$} & \multirow{2}{*}{$\begin{array}{l}\% \text { of } \\
\text { total acrobes } \\
(121)\end{array}$} \\
\hline & & Male & Female & & \\
\hline S. aureus & 1 & $15(12.3)$ & $19(15.7)$ & $34(28)$ & 28.1 \\
\hline P.aeruginosa & 2 & $11(9)$ & $14(11.5)$ & 25 & 20.7 \\
\hline K.pneumoniae & 3 & $6(5)$ & $7(5.7)$ & 13 & 10.8 \\
\hline S.pyogene & 4 & $3(2.4)$ & $7(5.7)$ & 10 & 8.3 \\
\hline E.coli & 5 & $3(2.4)$ & $5(4.1)$ & 8 & 6.6 \\
\hline $\begin{array}{l}\text { Serratia } \\
\text { marcescense }\end{array}$ & 6 & $2(1.6)$ & $3(2.4)$ & 5 & 4.1 \\
\hline $\begin{array}{l}\text { Acinetobactar } \\
\text { calcoceticus }\end{array}$ & 7 & $2(1.6)$ & $3(2.4)$ & 5 & 4.1 \\
\hline $\begin{array}{l}\text { Chryseomonas } \\
\text { meningosepticm }\end{array}$ & 8 & $1(0.8)$ & $2(1.6)$ & 3 & 2.4 \\
\hline Candida albicans & 9 & $1(0.8)$ & $2(1.6)$ & 3 & 2.4 \\
\hline $\begin{array}{r}\text { Providencia } \\
\text { stuartii }\end{array}$ & 10 & $1(0.8)$ & $2(1.6)$ & 3 & 2.4 \\
\hline Pantoea spcies & 11 & $0(0)$ & $2(1.6)$ & 2 & 1.7 \\
\hline S.typhi & 12 & $0(0)$ & $1(0.8)$ & 1 & 0.8 \\
\hline $\begin{array}{r}\text { Aerononans } \\
\text { caviae } \\
\end{array}$ & 13 & $0(0)$ & $1(0.8)$ & 1 & 0.8 \\
\hline $\begin{array}{r}\text { Enterobactar } \\
\text { aerogene }\end{array}$ & 14 & $0(0)$ & $2(1.6)$ & 2 & 1.7 \\
\hline S.virdiance & 15 & $2(1.6)$ & $0(0)$ & 2 & 1.7 \\
\hline P.vulgaris & 16 & $1(1.6)$ & $1(1.6)$ & 2 & 1.7 \\
\hline P.rettgeri & 17 & $1(1.6)$ & $1(1.6)$ & 2 & 1.7 \\
\hline \multirow[t]{2}{*}{$\begin{array}{c}\text { Total of aerobic } \\
\text { bacteria }\end{array}$} & 18 & $49(40.4)$ & $72(59.6)$ & $121(100)$ & 100 \\
\hline & 19 & $0(0)$ & $1(100)$ & 1 & \\
\hline Total & & $49(40.2)$ & $73(59.8)$ & 122 & \\
\hline
\end{tabular}

The total number of aerobic bacteria isolated was 121, representing 72(59.6\%) from female and $49(40.4 \%)$ from males. One type of anaerobic bacteria was isolated from the septicemic burn patient was Clostridium welchii in female patient.

The most frequent combination was that of P.aeruginosa and S. aureus 3(13.7\%) and the impact of seasonal variation upon this pattern was significant with more dispersed distribution over three seasons but mainly in the winter. Next in frequency was P.aeruginosa and E.coli 2(9.1\%) dispersed distribution over two season winter and spring. The largest number of sepsis burned patients occurred during winter $55 \%$ and the least number of patients occur during the spring $13 \%$.

The total number of isolated bacteria from the burn wound in male patients was 66(37.7) and from this bacteria 49(40.1\%) invade deep to the blood circulation. On the other hand, in female patients $109(62.3 \%$ ) was isolated from the burn wound and from this $73(59.9 \%)$ bacteria invade deep to the blood circulation.

Out of $175(100 \%)$ total number of bacteria isolated from the burn wound for both male and female for all patients 122 bacteria reached the blood.

Out of 39 isolate of S.aureus from the burn wound, $34(87 \%)$ of them reached the blood circulation.

Salmonella typhi and Aeromonas caviae were isolated from the blood of the septicemic burn patients and not found on the burn wound, indicating an underlying infection.

Serratia plymuthica and K.oxytoca were only isolated from the burn wound and did not invade the blood circulation. 
The isolated anaerobic bacteria (Clostridium perfringins ) was isolated from both the burn wound and the blood of the same female patient.

Antimicrobial susceptibility pattern of the isolated bacteria. S.aureus isolate were susceptible to vancomycin 31(91.2\%) and chloramphenicol 26(76.4\%). Amikacin was the most effective agent against all gram negative bacterial isolate, P. aeruginosa (68\%), proteus $(75 \%)$, K.pneumonia (84.6\%), E.coli (87.5\%) and Enterobacter (100). Polymyxin B was the second effective antimicrobial agent against P.aeruginosa (60\%).

\section{DISCUSSION}

Burn septicemia is a potentially life threatening clinical emergency that demand urgent diagnosis and treatment and it is probably the most serious complication of burn (Bang et al., 2017).

The usage of large variety of antimicrobial agents in hospitals burn wards, has lead to a change in the etiological agents and their antimicrobial resistance schema along different years (Pruitt and McManus, 2000)

It has been reported that the old age is an important predisposing factor of septicemia. In the present the highest rate of hospitalized septicemic burn patients was 23(23\%) in both sexes at age group (20-29) years old. This age represent the age of motility, activity, and much more contact with flame. The least frequent septicemic patients was $2(2 \%)$ at the age above 60 years, this may be due to decrease motility, activity and less contact with flame. This results is in agreement with the finding of Bang et al. (2017).

In this study the commonest cause of burn was flame (78\%), the scaled was (19\%) the electrical $(2 \%)$ and chemical burn (1\%) were are this result is in agreement with barrair et al., (2017).

Deep burn are essentially a vascular, so systemic delivery of antibiotics via the blood stream does not substantially affect microbiological growth within the burn wound.

Briar et al. (2017) reported that patients with burn more than $60 \%$ of total body surface area (TBSA) had $100 \%$ mortality, while those with $20-30 \%$ of TBSA had $20 \%$ mortality. Reported that mortality increase with severity of the burn injury and with increasing age of the patients.

Male septicemic burn patients were more vulnerable to death $(56 \%)$ from female patients (44\%). This finding is constituent with the finding of (Diller, 2001). The mortality rate was increased with the increasing of the burn degree. In $2^{\text {nd }}$ degree septic burn the death percentage was $(28 \%)$, while $3^{\text {rd }}$ degree it was $(76 \%)$.

Staphylococcus aureus was the most common isolated bacteria (28.1\%) from the blood of patients as a causative agents of septicemic attack followed by p.aeruginosa $(20.7 \%)$. This result was compatible with that of (Lessave et al., 2000) that reported that S.aureus has emerged as the most predominant organism and pathogen in resent years causing septicemia in the extensively burned patients.

Pseudomonas aeruginosa was the second most common isolated bacteria from the blood of patients. Nohoba et al. (2001) and Gang et al. (2000) found that pseudomonas was predominant and the most common organism in causing burn septicemia.

In the currently available drugs, Gentamycin, tobramycin and carbinicillin are the most effective, however there have been increasing numbers of reports of resistance to these antibiotics (Sutter and Hurst, 1999) especially when single drug is employed.

Klebsiella pneumonia was the $3^{\text {rd }}$ bacteria $(10.8 \%)$ isolated from the blood of septicemic burn patients followed by B-haemolytic S. pyogene, E.coli, Serratia marcescence, Acinetobacter calcoceticus, Chryseomonas meningosepticum, Providencia stuartii, pantoea, Enterobacter aerogene, P.vulgaris, P.retgeri, S.viridance and Aeromonas caviae (Sanyal et al., 2000) reported that the common species isolated were S.aureus and S.pyogene among gram positive bacteria while P.aeruginsa, K.pnemonia, E.coli, Serratia marcesence, Acinetobacter cacoceticua and proteus species were commonly isolated among gram negative bacteria. 
In this study one blood culture sample yielded S.typhi in enteric fever and septicemia, blood culture often positive in the $1^{\text {st }}$ week of the disease (Baron and Finegold, 2005). In conclusion this isolated case might be typhoid infection rather than burn septicemia.

Regarding anaerobic bacteria was isolated in single case Clostidinm welchii this pathogen was isolated from the blood of septicemic burn patient and she was a Kid 4 years old she had gas gangrene in the hand and abdomen after extensive burn.

Clostridium welchii natural habitat is the soil and intestinal tract of animals and human can survive and multiply only in tissue where there is low oxygen tension produce gas gangrene (Simmon, 2001).

Most bacteria which were isolated from the burn wound were isolated also from the blood circulation of the same septicemic burn patients with the same sequence but higher rates for the burn isolate, Bang et al. (2017) reported that most virulent pathogenic bacteria have the ability to penetrate the burn wound in extensively burned patients with dysfunction immune system deep to the blood circulation.

This study revealed that there was no difference between the sex distribution in relation to the potency of invading to the bacteria between male and female. This result disagree with that of Nohoba et al. (2001) reported that the male burn patients are more resistant to septicemic attack and the invading bacteria are less than that in burn wound, and female patients are more vulnerable to sepsis attack and less resist to invading pathogenic microorganism.

Prophylactic antibiotics treatment vary according to many variables like the extent and depth of burn, age of the patient, general condition of the patient, policy of the department and the issue of availability, antibiotic therapy is very necessary to administered if infection is already exist or the patient is more vulnerable to develop septic complication.

The most common gram positive bacteria was S.aureus, this bacteria was susceptible to vancomycin. Most of the Staphylococcus isolate were resistant to ampicillin, tetracycline, cephalothin, clindamycin,rifampicin and erythromycin and less resistant against chloramphenicol and cefotaxime. This result in agreement with Jawetz (2001) and Prasanna and Thomas (2002) who reported that vancomycin was the antibiotic to which most methicillin resistant S.aureus (MRSA) culture were susceptible.

Most gram negative bacteria isolated during this study were susceptible to amikacin, this may be due to that this antimicrobial agent was not commonly used, so the bacteria did not show any resistance against the antimicrobial agent.

Most gram negative bacteria appeared resistant to most to most of antimicrobial agents e.g ampicillin, cefotaxime, gentamycin, tobramycin, tetracycline, chloramphenicol and rifampicin. This reveal the multiple resistance of such nosocomial infections. This result in agreement with the study reported by (Baron and Peterson, 2005). Who found that multiple resistance is common among hospital strains of gram negative bacteria, those involve in serious nosocomial infections.

In this study P.aeruginosa was mostly susceptible to amikacin, polymexin-B but was resistant to other antimicrobial agents.

Barriar et al. (2017) found that multi drug resistance was more common with P.aeruginosa and the resistance to aminoglycoside had subsequently appeared in E.coli .

\section{CONCLUSIONS}

The highest mortality rate was among age group above 60 years old in addition at age group less than one year due to septicemic attack, male septicemic burn patients were more vulnerable to death mortality rate from female patients, male patients are less resistant to pathophysiological effect of the burn wound than that from female. The Risks factors (extant and depth of burn, age of patients and medical disease) are important predisposing factors for sepsis development.

All septicemic burn patients showed positive blood cultures inspite of their treatment with antibiotics. The most common isolated organism from the blood of patients as a causative agent of septicemic attack is S.aureus followed by P.aeruginosa, K.pneumonia, S.pyogenes and E. coli,one type of anaerobic bacteria was isolated in single case which was C.welchii infecting the burn wound and 
causing gas gangrene. A mikacin was the most effective agent against all gram negative bacterial isolate while vancomycin was the most effective against gram positive.

\section{REFERENCES}

Aladin, A.S.; Yousif, Z. (2016). "Guide to Chemotherapy and Chemoprophylaxis in Bacterial Infections". V2, $3^{\text {rd }}$ ed. USA. pp. 22-35.

Bang, R.L.; Gang, P.K.; Sanyal, S.C.; Mokaddas, E.; Ebrahim, M.K. (2017). Burn septicemia : an analysis of 79 patients. Burn. 24(4), 345-61.

Baron, E.J.; Finegold, S.M. (2013). "Baily and Scott. Diagnostic Microbiology". $13^{\text {th }}$ ed., Mosby. Toronto. pp. 138-139.

Baron, E.J.; Peterson, L.R. (2005). "Baily and Scott. Diagnostic Microbiology". $5^{\text {th }}$ ed., Mosby. Toronto. pp. 91-108.

Barrair, L.M.; Vasenwala, S.M.; Malik, A.; Ansari, G.H.; Chowdhury, T.E. (2017). Clinicopathological study of infection in burn patients and importance of biopsy. J. Indian-Med-Assoc. Nov.; 95(11), 573-5.

Bauer, Q.W.; Kirby, W.M.M.; Sherries, J.C.; Turck, M. (1966). Antibiotic susceptibility test by a stander dized single disc method. Am. J. Clin. Pathol. (45), 493-96.

Cruickshank, R.; Duguid, J.P.; Marimon, B.P.; Swain, R.H.A. (2013). "Medical Microbiology". Vol.2. $4^{\text {th }}$ ed., Newzland. 123 p.

Curtis, P.; Artz, M.D.; F.A.C.S.; John, A.; Monocrife, M.D.; F.A.C.S. (2015). " The Treatment of Burn". $2^{\text {nd }}$ ed. London. 10, pp. 305-310.

Diller, K.R. (2001). Analysis of burn caused by long term exposure to a heating pad. J. Burn Care Rehabil. 2(12), 214.

Gang, R.K.; Sanyal, S.C.; Bang, R.L.; MoKaddas, Lari. (2000). Staphylococcal septicemia in burn. Albabtain center for plastic surgery and burns. Ibn Sina Hospital Kuwait, 26(4), 359-66.

Higgins, C. (2014). Microbiological examination of blood for septicemia patients. Nurse-Times, Apr., 19-25 (16), 34-5.

Jawetz, Melnick and Adelbergs medical microbiology. (2001). Pathogenesis of Bacterial Infection. Chapter 9, pp. 115-130.

Lesseva, M.I.; Hadjiski, O.G. (2000). Staphylococcus infection in the Sofia burn center. Bulgaria. Burns. 22, 279-82.

Liedberg, N.C.F.; Kuhn, L.R.; Barnes, B.A.; Reiss, E.; Amspacher, W.H. (2011). Infection in burn, the pathogenicity of streptococci. Surg. Gynec. and Obst. 98,693.

Muir, I.F.K.; Bareclay ,T.L.; Settle, J.A.D. (2010). "Mode and Source of Infections: Burns and their Treatment". $3^{\text {rd }}$ ed. Butter Worth's, United kingdom. 20(8), 112-14.

Nogoba, B.S.; Deshmukh, S.R.; Wadher, B.J.; Pathan, A.B. (2001). Bacteriological analysis of burn sepsis . Indian J. Med, Sci., 53(5), 216-219.

Prasanna, M.; Thomas, (2002). A profile of methicillin resistant staphylococcus aurous infection in the burn center of the Sultanate Oman. Burns. 24 (7), 631-60.

Pregg, S.P. (2000). Multiple resistant staphylococcus aureus. Sep., 21(5),664-6.

Pruitt, A.B.Jr (2012). Infection caused by pseudomonas species in patient with burn and in other surgical patients. J. Infect.Dis., $\mathbf{1 3 0}$ (supl.), S8-S13.

Pruitt, B.A.; Jr McManus, A.T. (2000). The changing epidemiology of infection in burn patients. World J. Surg. 16, 57-67.

Reig, A.; Tejerina, C.; Codina, J.; Merabit, V. (2001). "Infection in Burn Patients". Department of Plastic Surgery and Burn Center, Hospital La Fe, Valencia, Spain.

Sanyal, S.C.; Mokaddas, E.M.; Gang, R.X.; Bang, R.L. (2000). Microbiology of septicemia in burn patients. Albabtain center for plastic surgery and Burns, Ibn Sina Hospital, Kuwait. Nurs Times. Apr 19(16), 34-5.

Simmon, S.M.D. (2001). A review of the complication of the burns, their origin and importance for illness and death. Am J. Infection control. 11,113. 
Sutter, V.L.; Hurst, V. (1999). Source of pseudomonas aeruginosa infection in burns, study of wound and rectal culture with phage typing. Ann. Surg., 163,597-602. 